\title{
Prevalence of confirmed immunoglobulin E-mediated food allergy among adult Egyptian patients
}

The Egyptian Journal of Immunology Volume 28 (1), 2021: 23-32. www.Ejimmunology.org

\section{Manar F Mohamed ${ }^{1}$, Dahab N Zakaraya ${ }^{1}$, Hoda E Abd-El Wahab ${ }^{2}$ and Zeinab A Ashour ${ }^{1}$}

\author{
${ }^{1}$ Department of Internal Medicine, Allergy \& Clinical \\ Immunology, Faculty of Medicine, Ain Shams University, \\ Cairo, Egypt. \\ ${ }^{2}$ Department of Clinical Pathology, Faculty of Medicine, Ain \\ Shams University, Cairo, Egypt.
}

Corresponding author: Manar F Mohamed, Department of Internal Medicine, Allergy \& Clinical Immunology, Faculty of Medicine, Ain Shams University, Cairo, Egypt. 38 El-Abaseya, Cairo 11566, Egypt.

Email: drmanarfarouk86@yahoo.com

\begin{abstract}
Food allergy (FA) represents an increasing social and economic health problem. Prevalence of food allergy differs from one country to another depending on genetic and environmental as well as feeding habits of each country. Estimate the prevalence of confirmed immunoglobulin E-mediated food allergy (FA) among adult Egyptian patients and identify its possible risk factors. A total of 2081 adult subjects were randomly selected from the Allergy outpatient clinic at Ain Shams university hospitals. Patients who disclosed food adverse complaints (probable food allergy group) were further subjected to a detailed questionnaire, complete blood cell count, total immunoglobulin E level, skin prick test and /or specific immunoglobulin E test for common food allergens, and oral food challenge with the culprit food. Patients were classified into confirmed food allergy and no food allergy groups depending on the results of oral food challenge test. Out of the 2081 adults, 100 subjects had selfreported food adverse complaints, and of them, $45(45 \%)$ had confirmed diagnosis of FA. Thirty four (75.6\%) confirmed FA patients were females with mean age \pm SD of $(38.02 \pm 13.08)$ years, five patients (11.1\%) had persistent childhood FA, 11 (24.4\%) had family history of atopy, five (11.1\%) had associated atopic diseases and 24 (53.3\%) were polysensitized. Female gender, young age and exercise were found to be risk factors for confirmed FA (OR: 1.766, 1.4, and 1.9 respectively). Cutaneous manifestations were the most common presentation of confirmed FA patients in the form of urticaria $40 / 45$ (88.9\%) and angioedema 18/45 (40\%). The most common food allergen was milk, banana, fish, tomato, strawberry and eggs. In conclusion, IgE mediated food allergy is a noticeable health problem among adult Egyptians, particularly adult females and young age groups.
\end{abstract}

Key words: Oral food challenge test, Food allergy, Immunoglobulin E (IgE), Allergen, urticaria

Date received: 23 December 2020; accepted: 22 January 2021

\section{Introduction}

Food allergy is a consistently increasing social and economic health problem that was thought to be confined to the industrialized countries. Nowadays, this disorder is of increasing prevalence among the developing countries, which may be due to urbanization and rapid economic rising. ${ }^{1}$ It is an adverse immune reactivity to certain food protein leading to reactions ranging from a mild response to a severe, life-threatening anaphylaxis. ${ }^{2}$ It is thought to be due to loss of natural oral tolerance, which is mediated through T- 
regulatory cells leading to shifting from Thelper-2 (Th2) pathway, increased interleukin (IL)-10 production, and class switching of B lymphocytes to produce immunoglobulin IgG and IgA instead of IgE with further suppression of mast cells, eosinophils, and basophils. ${ }^{3}$

Previous studies have identified several risk factors that increase the possibility of developing food allergy. Some of these factors are unavoidable, such as genetic predisposition, gender, and ethnicity. In addition, a number of modifiable risk factors have been identified including associated atopic diseases, vitamin D deficiency, and hygienic conditions. ${ }^{4,5}$

The estimated prevalence of food allergy differs from a country to another and even within the same country according to the diagnostic bases; whether it is self-reported or based on oral food challenge (OFC). ${ }^{6}$ The prevalence of a confirmed food allergy ranges from 6 to $10 \%$ among children ${ }^{7}$ and from 2 to $5 \%$ in adults. ${ }^{8}$ The most common food involved are cow's milk, egg, wheat, soya, tree nut, peanut, and shellfish. ${ }^{9}$ Some children with food allergy may develop natural tolerance around the age of 5 years toward cow's milk and egg; however, some allergies persist to adulthood, especially shellfish and tree nut allergies. ${ }^{10}$

This study aimed to estimate the prevalence of IgE-mediated food allergy among adult Egyptian patients attending the Allergy outpatient clinic at Ain Shams University hospitals and to identify its possible risk factors.

\section{Patients and Methods}

\section{Methods}

\section{Study design}

This cross-sectional study included 2081 adult subjects ( $\geq 16$ years-old) presented to the Allergy Clinic at our tertiary healthcare centre during the period from February 2019 throughout February 2020. They were evaluated for history of any food adverse reactions including dermatological (urticaria, itching), respiratory (rhinitis, wheezes), and gastrointestinal (abdominal pain, nausea, vomiting, diarrhea) symptoms. The 100 Patients who disclosed food adverse complaints were further subjected to detailed food allergy questionnaires and clinical examination.
Laboratory investigations included complete blood count, total IgE level, skin prick test (SPT) and/ or food specific IgE and oral food challenge (OFC). Depending on the results of OFC, patients were divided into confirmed food allergy group and no food allergy group. (Figure 1)

Patients with history of food-induced anaphylaxis or food-dependent, exerciseinduced anaphylaxis were excluded from the study. Also, patients with severe uncontrolled bronchial asthma or atopic dermatitis and those on allergen immunotherapy were excluded. Written consent was taken from all the participants after explaining the aim of the study and ensuring the confidentiality of the data.

\section{Questionnaire}

A questionnaire was designed to differentiate food allergy from other food-related adverse events, such as food intolerance and food intoxication and to detect the most likely causative food. In addition, the questionnaire investigated the time taken for symptoms to appear after food ingestion, history of eating the same diet before without symptoms, possibility of food cross contamination, history of taking drugs especially non-steroidal antiinflammatory drugs (NSAID), history of exercise before or after food ingestion as well as personal and family history of atopy and associated diseases, especially diabetes and hypertension. ${ }^{11}$

\section{Skin prick test}

We used common standardized food allergen extracts provided by Hamilton (Omega, Allergy OVERSEAS consultants Inc., Canada) including : milk, wheat, banana, strawberry, coca, tomato, fish, meat, chicken, shrimps, soya bean, carrot, casein, gluten, egg white, egg yolk, rice, potato, hazelnut, parsley, legumes, peanut, mango plus histamine as a positive control and saline as a negative control. We applied allergens on volar aspect of the forearm via a prick done with Prick Lancetter. We interpreted the results 20 minutes later, The test was considered positive when the wheel size was $3 \mathrm{~mm}$ or more. ${ }^{12}$

Food serum specific IgE tests

Food Specific IgE test is an enzyme immunoassay (EIA) for the quantitative 
determination of specific IgE. It was done for the following allergens (raw milk, egg white, egg yolk, wheat flour, chicken, fish, hazelnuts, peanut, meat, tomato, strawberries and banana). The test is a cellulose disc-based enzyme allergosorbent test (EAST) using the kits of RIDASCREEN Spec. IgE supplied R-Biopharm AG, An der neuen Bergstraße 17, D-64297 Darmstadt, Germany. In principle, allergens are attached to cellulose discs placed in the wells of a microwell plate. Patients' sera containing allergen specific IgE, an anti-human IgE antibody conjugated with alkaline phosphatase were added, multiple washing steps were done to remove the unattached conjugate. After that a substrate was added causing interactions yielded a yellow colour. A photometric measurement was then carried out at $405 \mathrm{~nm}$ using a reference wavelength of $620 \mathrm{~nm}$. Standards for the test included five standards ( 0.35 to $50.00 \mathrm{IU} / \mathrm{ml})$. For each test, we run the standards (in duplicate) as well as the positive and negative control on the same plate.

The standard curve for RIDASCREEN Spec. IgE is calibrated against the International reference preparation "2nd WHO IRP 75/502 for human $\operatorname{lgE}$, where specific IgE is considered positive if $\geq$ $0.35 \mathrm{IU} / \mathrm{mL}^{13}$

\section{Food elimination}

The study participants were advised to eliminate the suspected food from diet for two weeks with monitoring of symptoms through patients' diaries. ${ }^{14}$

Oral food challenge (open)
After two weeks of the culprit food elimination, all patients were advised to stop drugs that might interfere with the test results a week before the test, such as oral corticosteroids, oral antihistamines, antacids, proton pump inhibitors, or drugs that might interfere with rescue medications that might be given for allergic reactions such as beta blockers. Under our allergy team supervision, an open OFC was done, where both the doctor and patients knew the type of the introduced food. Patients were asked to introduce the culprit food every day for one week on gradually increased doses with documentation of any allergic symptoms that could occur during the first four to six hours from food introduction. The doses of food introduced were according to Nowak-Węgrzyn et al. recommendations ${ }^{15}$, as the involved foods were divided into portions according to their sizes using measurements such as grams and litres, millilitres. Starting with a sublingual drop size of the suspected food at the first day with increasing size of the served food gradually along the whole week. We stopped OFC when allergic reactions developed.

\section{Statistical analysis}

Data were analyzed using IBM SPSS software; Qualitative data were described using number and percent. The Kolmogorov-Smirnov test was used to verify the normality of distribution Quantitative data were described using range (minimum and maximum), mean, standard deviation, median and interquartile range (IQR). Chi square test was used to examine the relationship between two qualitative variables. $P<0.05$ : Significant (S) 




Figure 1. Flow chart of the study. 2081 adults who were randomly recruited from outpatient allergy clinic using systematic random method as the fourth patient were selected from every ten patients and so on. They were asked about self reported food adverse events. 100 subjects were found to have food adverse events (probable food allergy ) with further investigations were done, patients with positive oral food challenge were referred as confirmed food allergy group, patients with negative oral food challenge were referred as no food allergy group who were later diagnosed as mentioned above.

\section{Results}

2081 adult subjects who attended the outpatient allergy clinic at our tertiary healthcare centre during February 2019 throughout February 2020 were recruited and evaluated for self-reported food related adverse events. Of which 100 (4.8\%) subjects reported food adverse events, referred as (probable FA group), who needed further investigations to confirm FA diagnosis. After administration of detailed food allergy questionnaire, conduction of SPT and/ or food specific serum IgE, food elimination for two weeks followed by OFC and depending mainly on the final results of OFC, 45 out of 100 patients were found to have true food allergy and referred as (confirmed FA group). The other (55 patients) referred as (no FA group) were later diagnosed as chronic spontaneous urticaria (72.7\%), chronic allergic rhinitis not related to food (9\%), acute urticaria (7.27\%), bronchial asthma not related to food
(3.6\%), irritable bowel disease (3.6\%), and infectious diarrhea (3.6\%).

Regarding confirmed FA group, females were more predominant than males (75.6\%/ $24.4 \%)$, with mean age (38.02 \pm 13.08$)$ years. Five patients $(11.1 \%)$ had persistent food allergy since childhood while the other 40 patients (88.9\%) had adulthood newly developed food allergy, five patients had history of other associated atopic diseases. Only two patients had exercise-induced food allergy, while none of the patients reported history of allergy to drugs such as aspirin or other NSAID. About onefourth $(24.4 \%)$ of the patients had a family history of atopy. More than half (53.3\%) of confirmed food allergy patients were polysensitized. two patients were diabetic, and only one patient had associated hypertension (Table 1). 
Table 1. Description of demographic data and possible risk factors among confirmed food allergy patients

\begin{tabular}{|c|c|c|}
\hline \multirow{2}{*}{ Possible Risk factors } & \multicolumn{2}{|c|}{ Confirmed food allergy $(n=45)$} \\
\hline & No. & $\%$ \\
\hline \multicolumn{3}{|l|}{ Sex } \\
\hline Male & 11 & 24.4 \\
\hline Female & 34 & 75.6 \\
\hline \multicolumn{3}{|l|}{ Age years } \\
\hline Min. - Max. & \multicolumn{2}{|c|}{$19.0-72.0$} \\
\hline Mean \pm SD & \multicolumn{2}{|c|}{$38.02 \pm 13.08$} \\
\hline \multicolumn{3}{|c|}{ Associated allergic diseaseAtopy } \\
\hline Not associated & 40 & 88.9 \\
\hline Associated & 5 & 11.1 \\
\hline \multicolumn{3}{|c|}{ History of childhood food allergy } \\
\hline No & 40 & 88.9 \\
\hline Yes & 5 & 11.1 \\
\hline \multicolumn{3}{|l|}{ Co factor drugs } \\
\hline No & 45 & 100.0 \\
\hline Yes & 0 & 0.0 \\
\hline \multicolumn{3}{|l|}{ Co factor exercise } \\
\hline No & 44 & 97.8 \\
\hline Yes & 1 & 2.2 \\
\hline \multicolumn{3}{|l|}{ Family History } \\
\hline No & 34 & 75.6 \\
\hline Yes & 11 & 24.4 \\
\hline \multicolumn{3}{|l|}{ HTN } \\
\hline No & 44 & 97.8 \\
\hline Yes & 1 & 2.2 \\
\hline \multicolumn{3}{|l|}{ DM } \\
\hline No & 43 & 95.6 \\
\hline Yes & 2 & 4.4 \\
\hline \multicolumn{3}{|c|}{ Hyper sensitization state } \\
\hline Monosensitized & 21 & 46.7 \\
\hline Polysensitized & 24 & 53.3 \\
\hline
\end{tabular}

D.M, Diabetes mellitus; HTN, Hypertension; Data presented as n, (\%)except age presented as Mean \pm SD

After comparing confirmed FA group and no FA group for detection of possible risk factors, Female gender, younger age and exercise were found to be risk factors for food allergy development (odds ratio: $1.766,1.4$, and 1.9 respectively). in contrast, family history of atopy, history of associated atopic diseases and history of childhood food allergy were found not to be risk factors for food allergy development (odds ratio: 0.566, 0.55 and 0.97 respectively). (Table 2) 
Table 2. Comparison between confirmed food allergy and no food allergy groups in the term of different variables

\begin{tabular}{|c|c|c|c|c|c|c|}
\hline & $\mathrm{n}$ & $\begin{array}{l}\text { Confirmed } \\
\text { food } \\
\text { allergy\% }\end{array}$ & $\begin{array}{l}\text { no food } \\
\text { allergy } \\
n=55\end{array}$ & $\%$ & OR(95\%C.I) & $P$ value \\
\hline \multicolumn{7}{|l|}{ Sex } \\
\hline Female & 34 & $75.6 \%$ & 35 & $63.6 \%$ & \multirow{2}{*}{$1.76(0.736-4.233)$} & \multirow{2}{*}{ NS } \\
\hline Male & 11 & $24.4 \%$ & 20 & $36.4 \%$ & & \\
\hline \multicolumn{7}{|l|}{ Age (years) } \\
\hline$\geq 38.02$ & 20 & $44.4 \%$ & 20 & $36.4 \%$ & \multirow{2}{*}{$1.400(0.626-3.130)$} & \multirow{2}{*}{ NS } \\
\hline$<38.02$ & 25 & $55.6 \%$ & 35 & $63.4 \%$ & & \\
\hline $\begin{array}{l}\text { Associated } \\
\text { disease }\end{array}$ & \multicolumn{4}{|l|}{ allergic } & & \\
\hline Associated & 5 & $11.1 \%$ & 11 & $20.0 \%$ & \multirow{2}{*}{$0.500(0.160-1.564)$} & \multirow{2}{*}{ NS } \\
\hline Not associated & 40 & $88.9 \%$ & 44 & $80.0 \%$ & & \\
\hline \multicolumn{7}{|c|}{ History of childhood food allergy } \\
\hline Yes & 12 & $26.7 \%$ & 15 & $27.3 \%$ & \multirow{2}{*}{$0.970(0.399-2.357)$} & \multirow{2}{*}{0.946} \\
\hline No & 33 & $73.3 \%$ & 40 & $72.7 \%$ & & \\
\hline \multicolumn{7}{|l|}{ Co factor drugs } \\
\hline Yes & 0 & $0 \%$ & 0 & $0 \%$ & - & \multirow{2}{*}{-} \\
\hline No & 45 & $100 \%$ & 55 & $100 \%$ & - & \\
\hline \multicolumn{7}{|l|}{ Co factor exercise } \\
\hline Yes & 11 & $24.4 \%$ & 8 & $14.5 \%$ & \multirow{2}{*}{$1.901(0.691-5.229)$} & \multirow{2}{*}{ NS } \\
\hline No & 34 & $75.6 \%$ & 47 & $85.5 \%$ & & \\
\hline \multicolumn{7}{|l|}{ Family History } \\
\hline Yes & 11 & $24.4 \%$ & 20 & $36.4 \%$ & \multirow{2}{*}{$0.566(0.236-1.357)$} & \multirow{2}{*}{ NS } \\
\hline No & 34 & $75.6 \%$ & 35 & $63.6 \%$ & & \\
\hline \multicolumn{7}{|l|}{ HTN } \\
\hline Yes & 1 & $2.2 \%$ & 3 & $5.5 \%$ & \multirow{2}{*}{$0.394(0.040-3.923)$} & \multirow{2}{*}{ NS } \\
\hline No & 44 & $97.8 \%$ & 52 & $94.5 \%$ & & \\
\hline \multicolumn{7}{|l|}{ DM } \\
\hline Yes & 2 & $4.4 \%$ & 2 & $3.6 \%$ & \multirow{2}{*}{$1.233(0.167-9.115)$} & \multirow{2}{*}{ NS } \\
\hline No & 43 & $95.6 \%$ & 53 & $96.4 \%$ & & \\
\hline
\end{tabular}

D.M, Diabetes mellitus; HTN, Hypertension; Data presented as n, (\%); OR, odds ratio; Cl, Confidence interval; values are significant at $P>0.05$ is not significant(NS).

Among patients with confirmed FA dermatological manifestations were the most common (urticarial wheals, $88.9 \%$; pruritus, $82.2 \%$; and angioedema, $40 \%$ ) followed by gastrointestinal (nausea, 40\%; vomiting, 20\%; and diarrhea, $15.5 \%)$, and respiratory symptoms (rhinitis, 22.2\% and wheezes, 17.8\%). With regard to laboratory investigations, the median absolute eosinophil count was 190 cells $/ \mathrm{mm} 3$ $($ IQR $=30.0-150.0$ cells $/ \mathrm{mm} 3)$ and the median total IgE level was $140.0 \mathrm{IU} / \mathrm{mL}(\mathrm{IQR}=27.0-$ $220.0 \mathrm{IU} / \mathrm{mL}$ ).

The most common culprit foods were milk, banana, fish, tomato, strawberry, and egg among confirmed FA patients (Figure 2). After categorizing the patients of the confirmed food allergy group according to their ages into three groups : young adults (18-35 years old), middle age ( $36-55$ years old) and old age ( $>55$ years old), We found that FA was common among 
young adults (26 patients) than middle aged patients (13 patients) and older one (6 patients ), moreover milk, banana, strawberry and tomato were found to be common among young adult patients in contrast to middle and older age groups where milk, banana and fish were the most prominent. (Table 3)

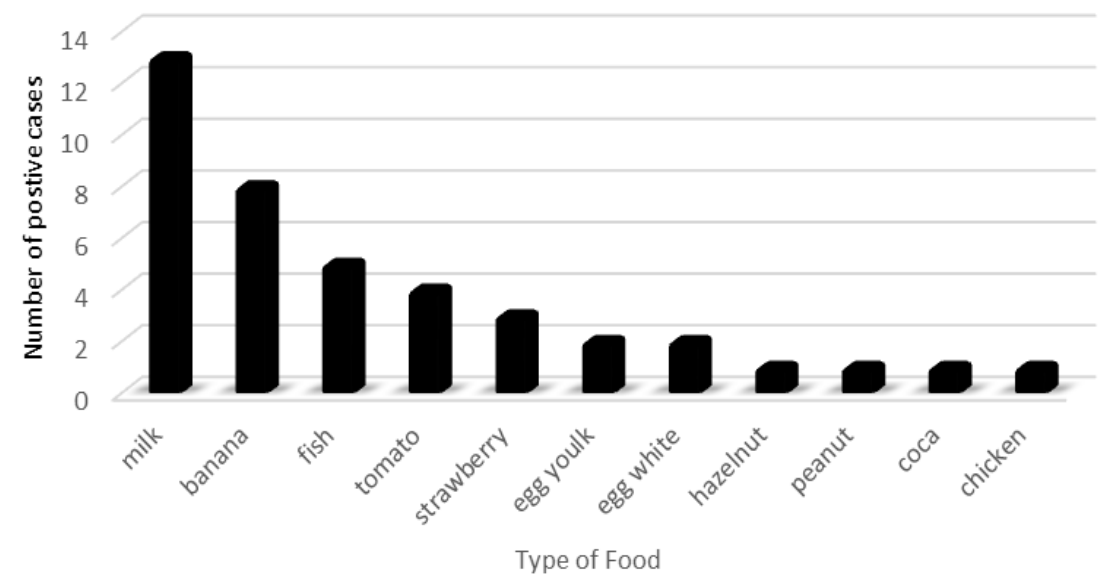

Figure 2. Distribution of food allergens according to skin prick test and OFC positive results in confirmed food allergy group. Patients with confirmed food allergy underwent skin prick test and open food challenge, the results showed that milk was the most common type of culprit food for food allergy, followed by banana, fish and tomato.

Table 3. Distribution of precipitating food according to age among patients with confirmed food allergy

\begin{tabular}{lccc} 
Type of food & $\begin{array}{c}\text { Young adults } \\
\text { 19-35 Years }(\mathrm{N}: 26)\end{array}$ & $\begin{array}{c}\text { Middle age } \\
\text { 36-55 Years }(\mathrm{N}: 13)\end{array}$ & $\begin{array}{c}\text { Old age } \\
>55 \text { Years }(\mathrm{N}: 6)\end{array}$ \\
Milk $(\mathrm{n})$ & 6 & 6 & 2 \\
Egg yolk $(\mathrm{n})$ & 3 & 1 & - \\
Egg white $(\mathrm{n})$ & 3 & 2 & - \\
Banana(n) & 6 & 5 & 2 \\
Fish $(\mathrm{n})$ & 3 & 3 & 1 \\
Tomato $(\mathrm{n})$ & 5 & - & - \\
Strawberry $(\mathrm{n})$ & 6 & 1 & - \\
Wheat $(\mathrm{n})$ & 1 & - & - \\
Hazelnut $(\mathrm{n})$ & 1 & - & - \\
Peanut $(\mathrm{n})$ & 1 & - & 1 \\
Meat $(\mathrm{n})$ & - & - & 1 \\
Chicken $(\mathrm{n})$ & - & - & \\
\hline
\end{tabular}

Data are presented as (n): number of positive cases

\section{Discussion}

Out of 2081 participants only 45 (2.16\%) patients had a confirmed food allergy diagnosis, with female predominance (75.6\%). Female Gender, younger age, and exercise were possible risk factors for FA. Food allergy presented mostly with dermatological manifestations, and the commonly involved food included milk, banana, fish, tomato, strawberry, and egg.

Various studies reported different prevalence rates for food allergy, which might be due to varied genetic and environmental factors, moreover the methods used for FA diagnosis. Comparable studies reported a prevalence rate of confirmed food allergy with OFC between $2.3 \%$ at Pakistan and $3.6 \%$ at the United 
States. ${ }^{16,17}$ Verrill et al. at the FDA Safety Survey in 2010 demonstrated that the prevalence rate of self-reported adult food allergy was $13 \%$, while the estimated prevalence of confirmed food allergy by the OFC was only $6.5 \% .{ }^{18}$ Similar results were found among adult Korean patients, with an overall prevalence rate of selfreported food allergy of $12.6 \%$, which was reduced down to $6.8 \%$ after history taking, specific IgE measurement, and skin prick testing. ${ }^{19}$

The current study pointed out some food allergy risk factors, such as gender. Most of our patients $(75.6 \%)$ were females, whereas only $24.4 \%$ of them were males. Several studies reported female predominance and high susceptibility to food allergy during adulthood. ${ }^{20-24}$ Other research work documented higher prevalence of food allergy among male children. ${ }^{16,25,26}$ These findings can be explained by the fact that after puberty, estrogens stimulate IgE production from B lymphocytes, causing polarization of Th2 pathway with subsequent production of IL-4, IL5 , and IL-13. On the other hand, androgens promote Th1 polarization with IL-2 production. ${ }^{25}$

In the current study, younger age groups (86.7\%) were susceptible to food allergy more than older age groups (13.3\%). This came in agreement with a Turkish study showing higher prevalence of food allergy among patients younger than 40 years-old. ${ }^{27}$ Our study recognized that only $11.1 \%$ of patients had persistent food allergy from childhood, while the majority $(88.9 \%)$ had a newly-developed food allergy. Beside gender and age, exercise was found to be a possible risk factor for food allergy development.

In this study, depending on history, SPT and confirmed with OFC results, more than half (53.3\%) of food allergy patients were polysensitized. This agrees with earlier studies confirming the higher prevalence of polysensitization in both children and adults. ${ }^{28,}$ ${ }^{29}$ Contrary to this, two different studies on adults and children declared that monosensitization for food allergens was more frequent than polysensitization. ${ }^{16,30}$

In the current study, patients with a confirmed food allergy presented mostly with dermatological manifestations including urticarial rash, itching, and angioedema. Less commonly, they had gastrointestinal (nausea and vomiting), and respiratory symptoms (running nose and wheezes). The majority of comparable studies confirmed that urticaria was the most common presentation of food allergies, and the least were rhino-respiratory manifestations. ${ }^{19,20,31,32}$

Regarding the most common food causing allergy, various studies show different results, which might be related to population differences in genetics, environment, and feeding habits. Moreover, disparity could be detected between the results of the SPT and the OFC in the same study population. The SPT reveals sensitization to a specific food rather than detecting hypersensitisation state. Sripramong et al. showed that the most common food with positive SPT results was sea food (crab and shellfish), while after performing OFC, cow's milk was the most common food explaining that the availability and local preference for seafood in Thailand might be the cause. $^{28}$

We detected that milk was the most common food causing allergy by both SPT and OFC, followed by banana, fish, strawberry, tomato, and egg; meanwhile, the least were wheat, coca, hazelnut, peanut, chicken, and meat equally. Likewise, earlier studies reported that cow's milk was the most common food causing allergy as detected by both SPT and OFC. $^{28,29,32,33}$ Nonetheless, wheat, egg, and strawberry have been identified as the first ranked food causing allergy among populations from Pakistan ${ }^{16}$, Kuwait ${ }^{21}$, and Lebanon ${ }^{20}$, respectively.

After categorizing ages of confirmed FA patients into three groups: young adults (18-35 years old), middle age (36-55 years old) and old age ( $>55$ years old) $)^{34}$, We found that milk, banana, strawberry and tomato were common among young adult patients, While in middle and older age groups milk, banana and fish were the most prominent. On the contrary, Kanny et al. demonstrated that egg and milk were commoner in children and younger adults, while fruits and fish were reported more frequently at older age groups. ${ }^{35}$

To the best of our knowledge, it is the first study in Egypt to detect the percentage of IgE mediated food allergy among adult Egyptian 
patients using OFC. Future studies aiming to detection of true prevalence of non-lgE mediated food allergy and studies involving new trends in food allergy diagnosis including basophil activation test or Component-resolved diagnosis are needed to be carried out for better identification of food allergy phenotypes and identification of cross reactive food for better management of food allergy. In conclusion Food allergy is a noticeable health problem among adult Egyptians, particularly female gender and younger age groups.

\section{Author Contributions}

ZA and $M M$, designed the study, MM wrote the manuscript. DZ and $\mathrm{MM}$ contributed to data collection. HA performed the statistical analysis and ZA performed the interpretation of the results. All authors read and approved the final manuscript.

\section{Declaration of Conflicting Interests}

The author (s) declared no financial or personal relationships with other people or organizations that could inappropriately influence that manuscript.

\section{Funding}

The author(s) denies receipt of any financial support for the research, authorship, and/or publication of this article.

\section{Ethical approval}

The study was approved from the Allergy and Clinical Immunology board at Ain Shams University in March 2019.

\section{Informed consent}

A signed consent form was obtained from each study participant.

\section{References}

1. Leung ASY, Wong GWK, Tang MLK. (2018) Food allergy in the developing world. J Allergy Clin Immunol. Jan;141(1):76-78.e1

2. Sicherer SH, Sampson HA. (2010) Food allergy. J Allergy Clin Immunol. Feb; 125 (2 Suppl 2):S11625.

3. Yu W, Freeland DMH, Nadeau KC. (2016) Food allergy: immune mechanisms, diagnosis and immunotherapy. Nat Rev Immunol. Dec; 16(12):751-765.
4. Hong X, Ladd-Acosta C, Hao K, et al. (2016) Epigenome-wide association study links sitespecific DNA methylation changes with cow's milk allergy. J Allergy Clin Immunol. Sep; 138(3):908-911.e9.

5. Sicherer SH, Sampson HA, Eichenfield LF, et al. (2017) The Benefits of New Guidelines to Prevent Peanut Allergy. Pediatrics. Jun; 139(6):e20164293.

6. Loh W, Tang MLK. (2018) The Epidemiology of Food Allergy in the Global Context. Int J Environ Res Public Health; 15(9):2043.

7. Sicherer SH, Sampson HA. (2018) Food allergy: A review and update on epidemiology, pathogenesis, diagnosis, prevention, and management. J Allergy Clin Immunol; 141(1):4158.

8. Kamdar TA, Peterson S, Lau CH, et al. (2015) Prevalence and characteristics of adult-onset food allergy. J Allergy Clin Immunol Pract; 3(1):114-5.e1.

9. National Academies of Sciences, Engineering, and Medicine; Health and Medicine Division; Food and Nutrition Board; Committee on Food Allergies: Global Burden, Causes, Treatment, Prevention, and Public Policy. Finding a Path to Safety in Food Allergy: Assessment of the Global Burden, Causes, Prevention, Management, and Public Policy. Oria MP, Stallings VA, editors. Washington (DC): National Academies Press (US); Nov 30.

10. Osborne NJ, Koplin JJ, Martin PE, et al. (2011) HealthNuts Investigators. Prevalence of challenge-proven IgE-mediated food allergy using population-based sampling and predetermined challenge criteria in infants. J Allergy Clin Immunol. Mar; 127(3):668-76.e1-2.

11. Sicherer SH, Muñoz-Furlong A, Sampson HA. (2003) Prevalence of peanut and tree nut allergy in the United States determined by means of a random digit dial telephone survey: a 5-year follow-up study. J Allergy Clin Immunol. Dec; 112(6):1203-7.

12. Heinzerling L, Mari A, Bergmann KC, et al. (2013) The skin prick test - European standards. Clin Transl Allergy. Feb 1;3(1):3

13. Kersten W., von Wahl P.G., Lange C.E., et al. (2000) in- vitro Diagnostik allergischer Erkrankungen [Recommendations for in vitro diagnosis of allergies]. Allergologie, Jg. 23, No. 6, 304-307.

14. Muraro A, Werfel T, Hoffmann-Sommergruber K, et al. (2014) EAACI Food Allergy and Anaphylaxis Guidelines Group. EAACl food allergy and anaphylaxis guidelines: diagnosis and 
management of food allergy. Allergy. Aug; 69(8):1008-25.

15. Nowak-Wegrzyn A, Assa'ad AH, Bahna SL, et al. (2009) Adverse Reactions to Food Committee of American Academy of Allergy, Asthma \& Immunology. Work Group report: oral food challenge testing. J Allergy Clin Immunol. Jun; 123(6 Suppl):S365-83.

16. Inam M, Shafique RH, Roohi N, et al. (2016) Prevalence of sensitization to food allergens and challenge proven food allergy in patients visiting allergy centers in Rawalpindi and Islamabad, Pakistan. Springerplus. Aug 11; 5(1):1330.

17. Acker WW, Plasek JM, Blumenthal KG, et al. (2017) Prevalence of food allergies and intolerances documented in electronic health records. J Allergy Clin Immunol. Dec; 140(6):15871591.e1.

18. Verrill L, Bruns R, Luccioli S. (2015) Prevalence of self-reported food allergy in U.S. adults: 2001, 2006, and 2010. Allergy Asthma Proc. Nov-Dec; 36(6):458-67.

19. Lee SC, Kim SR, Park KH, et al. (2019) Clinical Features and Culprit Food Allergens of Korean Adult Food Allergy Patients: A Cross-Sectional Single-Institute Study. Allergy Asthma Immunol Res. Sep; 11(5):723-735.

20. Irani C, Maalouly G. (2015) Prevalence of SelfReported Food Allergy in Lebanon: A MiddleEastern Taste. Int Sch Res Notices. Dec 16; 2015:639796.

21. Ali F. (2017) A Survey of Self-Reported Food Allergy and Food-Related Anaphylaxis among Young Adult Students at Kuwait University, Kuwait. Med Princ Pract; 26(3):229-234.

22. Afify SM, Pali-Schöll I. (2017) Adverse reactions to food: the female dominance - A secondary publication and update. World Allergy Organ J. Dec 27; 10(1):43.

23. Gupta RS, Warren CM, Smith BM, et al. (2019) Prevalence and Severity of Food Allergies Among US Adults. JAMA Netw Open. Jan 4;2(1):e185630.

24. Rentzos G, Johanson L, Goksör E, et al. (2019) Prevalence of food hypersensitivity in relation to IgE sensitisation to common food allergens among the general adult population in West Sweden. Clin Transl Allergy. Apr 1;9:22.

25. Kelly C, Gangur V. (2009) Sex Disparity in Food Allergy: Evidence from the PubMed Database. Journal of Allergy; 159845.

26. Willits EK, Park MA, Hartz MF, et al. (2018) Food Allergy: A Comprehensive Population-Based Cohort Study. Mayo Clin Proc. Oct; 93(10):14231430.

27. Gelincik A, Büyüköztürk $S$, Gül $H$, et al. (2008) Confirmed prevalence of food allergy and nonallergic food hypersensitivity in a Mediterranean population. Clin Exp Allergy. Aug; 38(8):1333-41.

28. Sripramong C, Visitsunthorn K, Srisuwatchari W, et al. (2019) Food sensitization and food allergy in allergic Thai patients from a tertiary care center in Thailand [published online ahead of print, 2019 Aug 18]. Asian Pac J Allergy Immunol; 10.12932/AP-210119-0475.

29. Gonzales-González VA, Díaz AM, Fernández K, et al. (2018) Prevalence of food allergens sensitization and food allergies in a group of allergic Honduran children. Allergy Asthma Clin Immunol; 14:23.

30. Fiocchi A, Pecora V, Petersson CJ, et al. (2015) Sensitization pattern to inhalant and food allergens in symptomatic children at first evaluation. Ital J Pediatr. Dec 8;41:96.

31. Sampson HA. (2004) Update on food allergy. J Allergy Clin Immunol. May; 113(5):805-19.

32. Choi Y, Ju S, Chang H. (2015) Food allergy knowledge, perception of food allergy labeling, and level of dietary practice: A comparison between children with and without food allergy experience. Nutr Res Pract; 9(1):92-98.

33. Sicherer SH, Wood RA, Vickery BP, et al. (2016) Impact of Allergic Reactions on Food-Specific IgE Concentrations and Skin Test Results. J Allergy Clin Immunol Pract. Mar-Apr; 4(2):239-45.e4.

34. Petry NM. (2002) A comparison of young, middleaged, and older adult treatment-seeking pathological gamblers. Gerontologist. Feb; 42(1):92-9.

35. Kanny G, Moneret-Vautrin DA, Flabbee J, et al. (2001) Population study of food allergy in France. J Allergy Clin Immunol; 108(1):133-140. 